\title{
A Comparison between Finland and China on Off-Campus Education of Primary and Secondary Schools
}

\author{
Qi He' ${ }^{1}$ Daoling Fu ${ }^{2}$ \\ ${ }^{1}$ International and Comparative Education Research Institute, College of Education, Southwest University, \\ Chongqing, China \\ ${ }^{2}$ The College of Physical Education, Southwest University, Chongqing, China \\ Email: fudaoling@163.com
}

Received 15 July 2014; revised 31 August 2014; accepted 17 September 2014

Copyright (C) 2014 by authors and Scientific Research Publishing Inc.

This work is licensed under the Creative Commons Attribution International License (CC BY).

http://creativecommons.org/licenses/by/4.0/

(c) (i) Open Access

\begin{abstract}
In 2011, the National Education Committee of Finland published "The Framework for Off-campus Education in Primary and Secondary Schools", which stipulated the goals, content, and implementing guarantee of the off-campus education in primary and secondary schools. Besides, while emphasizing the equal importance of on-campus and off-campus education, the "Framework" also advocated schools to actively deal with the challenges posed to off-campus education, ensured its high quality and efficiency from all aspects, and cultivated primary and secondary school students' emotional cognition, so as to enhance the level of their moral cognition. As a result, The "Framework" has profoundly promoted the development of off-campus education in Finnish primary and secondary schools. The off-campus education of china has certain problems relatively, such as the lack of system management, while quality is not guaranteed. However China has invested a lot of human, financial and material resources in basic education these years, and appropriate measures have been taken to address the problem of excessive burden on students. Moreover, much importance was attached to strengthening the construction and management of off-campus education sites, and enriching students' extracurricular education. The author's current study opted to compare Finland and China on Off-campus Education of Primary and Secondary Schools. Implications for Chinese education are discussed.
\end{abstract}

\section{Keywords}

Comparison, Primary and Secondary Education, Off-Campus Education

\section{Introduction}

In 2011, the National Education Committee of Finland published "The Framework for Off-campus Education in 
Primary and Secondary Schools”, whose goals, content, guiding principles, implementing regulations, and assessment criteria are highly consistent with its fiscal policy. The "Framework" entered into force on August 1 in that year when all the local authorities were required to modify the policies of off-campus education in accordance with "The Framework for Off-campus Education in Primary and Secondary Schools", seriously organize off-campus education, and equally treat on-campus education and off-campus education. China published "The National Medium- and Long-Term Plan for Education Reform and Development (2010 to 2020)”, which regards compulsory education as one of the eight tasks of development over the next 10 years. And one chapter was individually written to make deployment of education, in which much emphasis was put on reducing the academic burden on students, enabling students to have enough time to know the society, think in-depth, get hands-on practice, and do exercise as well as entertain themselves. Moreover, much importance was attached to strengthening the construction and management of off-campus education sites, and enriching students' extracurricular education [1].

\section{Background}

Although the "Basic Education Act” promulgated by Finnish government had clarified the relevant regulations for the off-campus education, it failed to be transformed into effective action. Now, the off-campus education in Finland is facing such problems as receiving low level of attention, excessive time of staying at home alone on the part of primary and secondary schoolchildren and difficulties of guaranteeing a healthy living environment.

\subsection{The Difference of Importance Attached to Primary and Secondary Education}

As early as in the 17th century, the Finnish people were required to learn to read from childhood and to read "the Bible". There is no doubt that the requirement from Christianity which was a combination of compulsoriness and encouragement has exerted profound impact on Finnish people who now are attaching great importance to education, especially to the basic education [2]. In 1998, the Finnish government issued the "Basic Education Act”, which provided that the objective of nine-year compulsory training was to teach basic knowledge and skills needed by children, cultivate their self-learning ability, make them love and willing to explore life, and turn them into members with basic knowledge and skills as well as morality [3].

At the end of 1950s, The Chinese communist youth league central ministry of education published "About the school education and the several provisions of the teenager's home work", who put forward the importance of school education clearly. At the same time put forward plan in order to guarantee the infrastructure construction of the school education. This is the first legal documents of off-campus education since the beginning of history, marking the beginning of off-campus education into the state's education system [4]. However, there were little followed details attached to the implement of Chinese off-campus education, off-campus education in China wasn't well developed.

\subsection{The Difference of the Status Quo of Off-Campus Education}

The average learning year for Finnish primary and secondary school students is 16.7 years [5], which is more than that of other European countries. Meanwhile, the relevant international survey statistics have showed that the students who hate school account for $26 \%$ of the total Finnish students [6]; those who feel bored about school life reach up to $60 \%$ [7]; $42 \%$ of the Finnish students have complained the confusion in classroom education [8], which ranks second in the whole Europe. All the above data shows that: Finnish students' learning time is relatively abundant, but there are some problems in the school education, such as confusion in classroom education, and students' low enthusiasm for learning. Besides, students have brought such negative emotions to the off-campus education, which makes the implementation of off-campus education unsatisfactory. In this sense, these factors have become obstacles to the development of education in Finland.

Chinese Primary and secondary school students' average study life is 12 years, including 9 years of compulsory education and 3 years of high school. For Chongqing Jiangbei district, students of Primary school spend about 6 hours in school on weekday, while have 2 days' relax at the weekend. Secondary school students have about 7 days in school on weekday, and also 2 days' relax at the weekend. However, high school students only have 1 day relax, while they should stay at school for 8 hours except Sunday. The data show that Chinese students' study time is abundant relatively and they have plenty of time for off-campus learning. 


\section{The Comparison of Goals and Content}

\subsection{Goals of Finland}

The goals set by Finnish government of off-campus education could be summarized into four points which are to supplement on-campus and family education, create rich sensory experience of life and society, develop correct moral values and foster such social consciousnesses as participation, cooperation and fairness.

\subsubsection{Supplementing On-Campus and Family Education}

The primary goal for the Finnish Government to set up off-campus is to supplement and complement the oncampus and family education [9]. Besides, to ensure the fairness and equality in the academic achievement of primary and secondary school students, Finland carries out an individualized education in the basic education stage. So pupils' personal ideas are fully respected in terms of the curriculum or the time schedule, and the type and content of teaching materials, lecturing forms and methods are all used based on their interest and needs.

\subsubsection{Creating Rich Sensory Experience of Life and Society}

Off-campus education provides a variety of activities for primary and secondary school students to enrich their sensory life. Such activities are carried out in the form of groups. Students form groups to accomplish a given task together, which could effectively train their ability to communicate with others. For example, they will stand in others' shoes when handling public affairs, use appropriate means to deal with differences in opinions, and learn to be accepted quickly by peer members in the collective activities. Therefore, these students will finally learn to behave themselves in accordance with different scenarios and environments through these practical training. In addition to the activities which could develop interest and specialties such as sports, music, craft activities that primary and secondary students are particularly interested in, there are also family activities aimed at creating opportunities for family members to play together and enhance communication [10].

\subsubsection{Developing Correct Moral Values}

There are two concepts running through off-campus education: correct moral values and equality of human rights. Primary and secondary school students will improve themselves through off-campus activities from five aspects: first, learn how to follow a healthy lifestyle; Second, learn how to make others' life more convenient; third, try to understand what kind of impact that their behavior could make whether directly or indirectly; fourth, learn how to follow the conventions in the community life; fifth, learn how to deal with an unfamiliar environment with a positive attitude. Off-campus education is mainly to cultivate civic awareness and responsibility in students, thus promoting the formation of their moral values [11].

\subsubsection{Cultivating Social Awareness of Participation, Cooperation and Fairness}

Another goal of off-campus education is to enable primary and secondary school students to garner achievement experience in activities, thus cultivating their social awareness of participation, cooperation and fairness. The allocation principle of Finland's basic education is fairness and equality. Cultural background, economic status, intellectual differences and regional differences are not the obstacles for students to receive excellent education in a fair manner; instead, they will become the reasons for the students to receive more attention on the allocation of education resources. Every agency holding activities has no right to publish any information about the performance of pupils without the authorization of their parents or guardians [12].

\subsection{Goals of China}

The goals set by Chinese government of off-campus education could be summarized into three points which are to developing correct moral values, developing hobby, Supplementing on-campus and family education.

\subsubsection{Developing Correct Moral Values}

The main undertaker of off-campus education is Youth palace for a long time. It is Children's off-campus education authorities in China. Its basic task is cooperating with school on communism education for young children. Primary and secondary school students will improve themselves through off-campus activities, and have correct moral values. 


\subsubsection{Developing Hobby}

In 2006, it is pointed out in the fourth file of government: the city and county's youth palace, the children's palace and children's activity center, etc. which should give play to the function of education and make it popularized, interesting and experienced. Considering the physical and mental characteristics of minors, youth palace should design and carry out widely popular, nationality and practical activities. To combine the school curriculum, youth palace should organize science and technology and other interest groups of community activities, make minors participating in various forms of outside activities, develop their interests and ability.

\subsubsection{Supplementing On-Campus and Family Education}

In 2006, the government published "The construction and management work on further strengthening and improving the minors' activities”, which combined the school curriculum with off-campus education, pointing that the government should overall arrange off-campus activities, according to the functions and features of different places. The off-campus education should be involved into basic education, making sure that students have half a day time participating in activities per week on average.

\section{The Comparison of Implement}

"The Framework for Off-campus Education in Primary and Secondary Schools" stipulates that any local district that is carrying out off-campus education should follow the regulations in the "Basic Education Act", should draw up the basic plans for activities, support the work of local districts, and standardize as well as improve the quality of off-campus education.

\subsection{Implement of Finland}

Policy: According to “The Framework for Off-campus Education in Primary and Secondary' Schools”, local authorities can either conduct off-campus education independently or jointly cooperate with other responsible authorities. Besides, they are permitted to buy a mature activity mode from public or private service providers to undertake off-campus education. Nevertheless, the public service providers must be the relevant departments in local governments, municipal bank systems or federal districts. They must sign a corresponding responsibility authorization letter, and are obliged to provide specific details of their plans. Students who encounter any difficulties in school life can apply for special needs education [13]. The plans of activities in off-campus education will be designed with great care for the students who need special education, and the structures of activities are clear [14]. The details of activities should include the following aspects: mission and goal, theme and planning principles, main factors involved in the activities such as the time, sites, and funds, mechanism for activities assessment, and exchange of activity information. The general framework of activities is applicable to all the primary and secondary school students, including the students who have needs for special education [15].

Time and sites of activities: As showed in the "The Framework for Off-campus Education in Primary and Secondary' Schools", the activity time for students each year should be between 570 hours and 760 hours. Families can make use of their available time to participate these activities according to their own circumstances. On weekdays, 3 - 4 hours must be organized for off-campus education every week; while at weekends, the time of education is from 7:00 a.m. to 5:00 p.m. Moreover, any student taking part in the off-campus education has the right to enjoy a safe activity environment. As for the sites of activities, the "Framework" provides that they had better be schools or places that are qualified and local authorities must ensure the security of the location and facilities. Furthermore, each site must have a valid escaping plan. School facilities are highly recommended to be used. If necessary, renovation of schools or building a new one is allowed. Last but not least, the environment of activities should take into account the interest and hobbies of the students, so as to contribute to the achievement of activity goals [16]. Finnish schools also provide diversified courses, including health, religion, ethics, history, society, music, visual arts, crafts, sports, economy and other elective courses catering to students' interest [17]. Therefore, off-campus education will cultivate four capabilities on the part of students which are respecting the culture and traditions of others, skillful use of hand tools, application of multimedia devices, reading texts and books [18].

Assessment: The National Education Committee of Finland is responsible for formulating basic assessment criteria of off-campus education, while the specific rules are developed by the local authorities. As the content and form of off-campus education in every region is different, there are differences in the assessment details. In general, 
assessment of off-campus education is conducted from three aspects: the first is self-assessment, which means that the assessment is achieved between teachers and teachers, teachers and students, students and parents; the second is platform assessment system. The process and results of the activities will be evaluated in the platform assessment system at a macro level so as to receive standardized inspection; the last one is announcement of the assessment results. The results will be published by the local authorities for the supervision of the whole community [19].

\subsection{Implement of China}

Policy: The introduction of China about off-campus education policy only stagnates on a poor level. As the government announces, the city and county's youth palace, the children's palace and children's activity center, etc. which should give play to the function of education and make it popularized, interesting and experienced. Considering the physical and mental characteristics of minors, youth palace should design and carry out widely popular, nationality and practical activities. To combine the school curriculum, youth palace should organize science and technology and other interest groups of community activities, make minors participating in various forms of outside activities, develop their interests and ability.

Time and sites of activities: According to "The construction and management work on further strengthening and improving the minors' activities”, which combined the school curriculum with off-campus education, which stipulate the off-campus education should be involved into basic education, making sure that students have half a day time participating in activities per week on average.

Assessment: Up to now, China has even not a special policy about off-campus education, nor a complete solution of how to deal with the problem. The latest documents which have mentioned off-campus education is “The National Medium- and Long-Term Plan for Education Reform and Development (2010 to 2020)", which have only one of the eight chapter sect discussing off-campus education. Generally speaking, China has not a systematic policy about off-campus education, nor the assessment.

\section{Implications for Chinese Education}

\subsection{On-Campus and Off-Campus Education Should Be Equally Emphasized}

Although our primary and secondary school students have wined the first prize in the PISA test in 2009 and in 2012 respectively, the time spent in school by them far exceeds that spent by the Finnish schoolchildren. Our students are overburdened with school tasks, which have become an obstacle to the healthy development of education. However, China has invested a lot of human, financial and material resources in basic education these years, and appropriate measures have been taken to address the problem of excessive burden on students. Besides, “The National Medium-and Long-Term Plan for Education Reform and Development (2010 to 2020)” was issued, which regards compulsory education as one of the eight tasks of development over the next 10 years. And one chapter was individually written to make deployment of education, in which much emphasis was put on reducing the academic burden on students, enabling students to have enough time to know the society, think in-depth, get hands-on practice, and do exercise as well as entertain themselves. Moreover, much importance was attached to strengthening the construction and management of off-campus education sites, and enriching students' extracurricular education [20]. In this way, we can gradually promote the development of off-campus education in primary and secondary schools, as well as accelerate a comprehensive, healthy, and happy learning and growth on the part of students.

\subsection{The Policy of Education Reform Should Be Elaborate}

The policy of education reform should have clear goals, specific content, and feasibility. For us, we should further improve our reform policies on primary and secondary education, perfecting the details in the provisions of the polices, regulate and standardize the implementation of off-campus education at a micro level [21].

In addition, we should clarify the rules on reducing primary and secondary schoolchildren's burden, provide a wealth of extracurricular activities to enrich the pupils' spare time, and effectively implement the policies about reducing students’ academic burden.

\subsection{The Implementation of Education Policies Should Be Guaranteed}

In order to ensure that the implementation of policies on education reform could be conducted as expected, it is 
essential for us to have a sound management system and related policy guarantees. And to make our policy of basic education successfully implemented, China should further improve the education management system, clarify the obligation and responsibilities on all levels of departments and regions, and create a dynamic and transparent monitoring and evaluation mechanism. In this way, we will successfully provide follow-up guarantees for the reduction of the academic burden on students, and the policies on reducing students' burden will be implemented in a real sense in the aspects of time, content, and finance.

\section{Conclusion}

This study is intended to compare off-campus education of primary and secondary school between Finland and China. In terms of the comparison of goals, contents and implementation, the results show that China has to make great efforts to catch up with others whose off-campus education is much better planed. Further research is needed on the content details required of Chinese in order to provide an understanding of what is the main goals of off-campus education, how to do and whether such content meets the needs of Chinese.

\section{References}

[1] Central People’s Government of the People’s Republic of China. The National Medium-and Long Term Plan for Education Reform and Development (2010 to 2020).

[2] The Finnish National Board of Education. Basic Education Act 1998 [EB/OL]. 2013-08-10. http://www.minedu.fi/OPM/Koulutus/perusopetus/?lang=en.pdf

[3] Chinese Youth Association, China Youth University for Political Sciences (2005) China Youth Education Policy Content Analysis and Performance Evaluation. China Children Press, Beijing, 52.

[4] Itkonen, T. and Jahnukainen, M. (2007) An Analysis of Accountability Policies in Finland and the United States. International Journal of Disability, Development and Education, 54, 5-23. http://dx.doi.org/10.1080/10349120601149664

[5] Nation Master. School Life Expectancy [EB/OL]. http://www.nationmaster.com/graph/edu_sch_lif_exp_tot-education-school-life-expectancy-total. 2013-09-15

[6] Nation Master. Student Attitude Dislike School [EB/OL]. http://www.nationmaster.com/country-info/stats/Education/Student-attitude/Report-class-disorder

[7] Nation Master. Student Attitude, Find School Boring [EB/OL]. 2013-09-15. http://www.nationmaster.com/graph/edu_stu_att_fin_sch_bor-student-attitude-find-school-boring

[8] Finland Education Stats [EB/L]. http://www.nationmaster.com/country-info/profiles/Finland/Education

[9] Finnish Ministry of Education and Culture. Education System in Finland [EB/OL]. 2013-08-12. http://www.minedu.fi/OPM/Koulutus/koulutusjaerjestelmae/index.html?lang=en

[10] The Finnish National Board of Education. National Framework for before- and after-School Activities in Basic Education $[\mathrm{EB} / \mathrm{OL}]$.

http://www.oph.fi/english/sources_of_information/core_curricula_and_qualification_requirements/before_and_after_sc hool_activities.pdf.2013-08-11.

[11] Lai, K.H. (1999) Civic Education: A Focus on Student Affairs Practice after Reunification. Educational Studies, 25, 205-215. http://dx.doi.org/10.1080/03055699997918

[12] The Finnish National Board of Education. National Core Curriculum for Basic Education [EB/OL]. http://www.oph.fi/download/47673_core_curricula_basic_education_4.pdf . 2013-08-11.

[13] Finnish Ministry of Education and Culture. Proudly Presents: Educational Support and Guidance [EB/OL]. 2013-08-23. http://www.minedu.fi/OPM/Verkkouutiset/2012/09/special_education.html?lang=en

[14] Joelkivitsuma and Kariruoho (2007) Excellence through special Education? Lessons from the Finnish School Reform. Review of Education, 53, 283-302.

[15] Halinen, I. and Jarvinen, R. (2008) Towards Inclusive Education: The Case of FINLAND. Prospects, 38, 77-97. http://dx.doi.org/10.1007/s11125-008-9061-2

[16] Yuan, L.Q. (2007) An Analysis of the Reasons for the Success of Finland's Basic Education. Primary \& Secondary Schooling Abroad, 12, 36-39.

[17] Ahonen, P. (2014) Administrative Research in a Neoinstitutionalist Perspective: Finland, Calling for Globalization, and the Rehabilitation of Public Administration. Administration \& Society, 46, 747-774. http://dx.doi.org/10.1177/0095399712461911 
[18] Giskes, K., Kunst, A.E. and Benach, J. (2005) Trends in Smoking Behaviour between 1985 and 2000 in Nine European Countries by Education. Journal of Epidemiology and Community Health, 59, 395-401. http://dx.doi.org/10.1136/jech.2004.025684

[19] Sahlberg, P.E. (2007) Education Policies for Raising Student Learning: The Finnish Approach. Journal of Education Policy, 22, 152.

[20] Central People’s Government of the People’s Republic of China. The National Medium-and Long-Term Plan for Education Reform and Development (2010 to 2020).

[21] Sahlberg, P.E. (2007) Education Policies for Raising Student Learning: The Finnish Approach. Journal of Education Policy, 22, 157. 
Scientific Research Publishing (SCIRP) is one of the largest Open Access journal publishers. It is currently publishing more than 200 open access, online, peer-reviewed journals covering a wide range of academic disciplines. SCIRP serves the worldwide academic communities and contributes to the progress and application of science with its publication.

Other selected journals from SCIRP are listed as below. Submit your manuscript to us via either submit@scirp.org or Online Submission Portal.
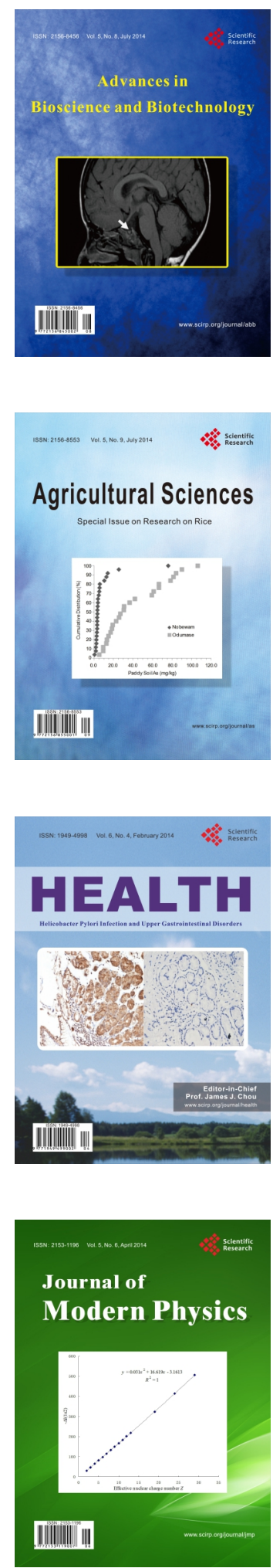
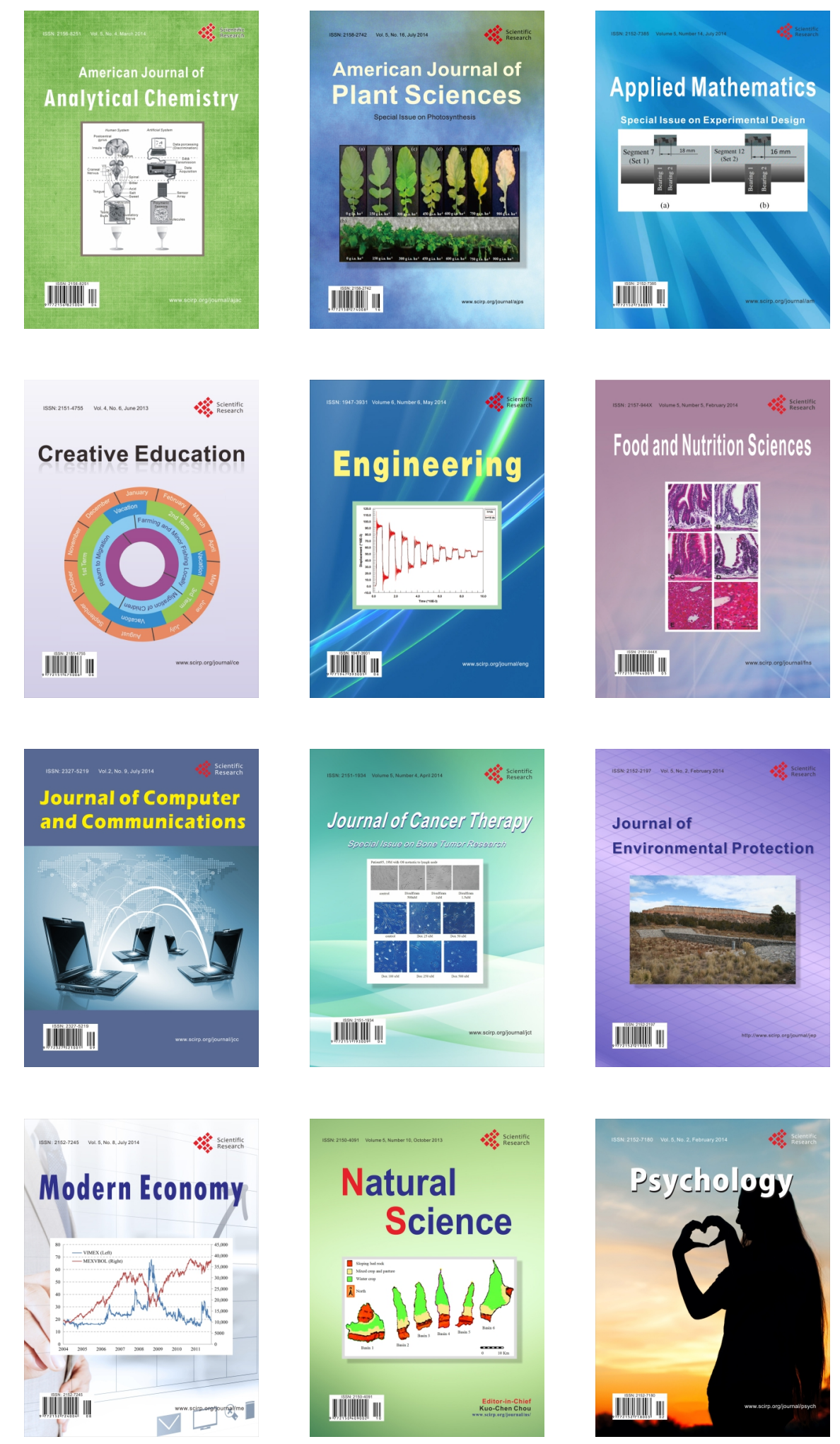